\title{
Maximum Likelihood Estimation of Parameters for Advanced Continuously Reinforced Concrete Pavement (CRCP) Punchout Calibration Model
}

\author{
Liangliang Chen $\mathbb{D}^{1},{ }^{1}$ Feng Zhang $\mathbb{D}^{2},{ }^{2}$ and Changjun Zhou ${ }^{3}{ }^{3}$ \\ ${ }^{1}$ National Engineering Laboratory for Surface Transportation Weather Impacts Prevention, \\ Broadvision Engineering Consultants, No. 9, Shijiaxiang Tuodong Road, Kunming 650041, China \\ ${ }^{2}$ School of Transportation Science and Engineering, Harbin Institute of Technology, No. 73, Huanghe Road, \\ Harbin 150090, China \\ ${ }^{3}$ School of Transportation and Logistics, Dalian University of Technology, 2 Linggong Street, Dalian 116023, China \\ Correspondence should be addressed to Liangliang Chen; dongtianai@163.com and Changjun Zhou; zhouchangjun@dlut.edu.cn
}

Received 18 June 2021; Accepted 24 August 2021; Published 3 September 2021

Academic Editor: Hugo Rodrigues

Copyright (c) 2021 Liangliang Chen et al. This is an open access article distributed under the Creative Commons Attribution License, which permits unrestricted use, distribution, and reproduction in any medium, provided the original work is properly cited.

\begin{abstract}
Pavement performance prediction is the essential part of the pavement design, which is very important for highway agencies for the purpose of budget allocating. This study introduces a model of local calibration for punchout, which is the major structural distress of continuously reinforced concrete pavement (CRCP). It is assumed that the number of equivalent single axle loads' (ESALs) leads to punchout follows a Weibull distribution. The parameters of Weibull distribution were estimated by maximum likelihood estimation (MLE). Additionally, an approach of estimating the initial value of the parameters was also presented before applying the Newton method for solving the likelihood equations. The regression result was found to fit the performancemonitoring data from LTPP very well. The proposed calibration model is capable of describing the punchout and can be employed to predict the failure rate and reliability of CRCP in the pavement design and the arrangement of rehabilitation activities.
\end{abstract}

\section{Introduction}

Predicting the pavement performance under various combinations of traffic levels, environmental conditions, pavement structures, and materials are a key component for highway agency to make a proper budget decision of the maintenance and rehabilitation activities [1]. Undoubtedly, the accuracy of the distress prediction depends on the calibration and validation of the mechanistic-empirical (ME) design models with independent datasets. Pavement engineers can definitely gain confidence in the design procedure when the ME models were calibrated by establishing an acceptable correlation between predicted and measured distresses in field. Local calibration is a systematic and mathematical process to minimize the difference between observed and predicted results by modifying, for instance, empirical calibration parameters that eventually would be found to be a function of the key factors as a means to improve the accuracy of the prediction models [2]. No mechanistic pavement design models can be applied in practice for pavement performance prediction without calibration due to the great variety of environmental conditions, pavement structures, materials, and traffic loads. In order to improve the accuracy, reliability, and robustness of the performance prediction model, field investigation data from LTPP was utilized in the calibration process [3]. LTPP database is worthy of the name of the largest pavement performance database, test sections from LTPP were used extensively in the calibration process, which can provide pavement engineers with historically recorded climate information, monitoring of distress and response, materials testing, maintenance, and especially pavement performance 
monitoring data. LTPP data were employed to conduct local and national calibration of the pavement performance by many researchers on both in-service flexible and rigid pavements [4-7], as well as survival analysis for preventive maintenance $[8,9]$.

However, as mentioned by Prozzi and Madanat [10], the pavement distress is an event of high variety, and it was more reasonable to describe the failure of pavement by a function of probability density rather than by a fixed-point estimation. It is worth noting that the distress investigation was not conducted continuously in LTPP data; moreover, the development of distresses is inconsistent [7]. The recording of punchouts as well as other types of distress is not simultaneous with the occurrence of pavement failure. Instead, only the number of punchouts formulated during the interval is available in the LTPP database. Pavement performance investigation is usually conducted at irregular intervals, ranging from 1-6 years. Therefore, the assumption that all the punchouts occur at the end of each interval will unavoidably underestimate the probability of the occurrence of punchouts.

The number of ESALs leading to punchout for a CRCP panel was assumed to follow Weibull distribution and the maximum likelihood estimation (MLE) of the parameters was introduced to estimate the parameters, due to insufficient data, to build the calibration model. The likelihood equations were solved by the Newton method, and least square regression was proposed to estimate the initial values. As a consequence, investigation data of field performance from LTPP GPS-5 (for CRCP) were extracted in Section 3 to illustrate the reliability and validity of the calibration procedure developed in this study.

\section{Calibration Model}

2.1. Weibull Distribution. Weibull distribution is the most popular and is widely used in the analysis of lifetime data and reliability since it was first introduced by Weibull in 1950s [11]. It has been proven to be very effective in modelling and analyzing lifetime data in medical, biological, and engineering sciences [12]. For instance, Weibull accelerated the failure time model and was successfully applied in prediction of pavement fatigue [13].

It is postulated that the fatigue process of pavement follows a Weibull distribution. The probability density of a two-parameter Weibull distribution is

$$
f(x ; \lambda, \beta)=\lambda \beta(\lambda x)^{\beta-1} e^{-(\lambda x)^{\beta}}, \quad x \geq 0 .
$$

The fatigue life pavement structures is defined as $T$ and the duration function $\mathrm{F}(t)$ indicates the probability that the pavements will be distressed, cracked, or punchout for CRCP until time $t$, say $P(T \leq t)$; thus,

$$
F(t)=P(T \leq t)=1-e^{-(\lambda t)^{\beta}}, \quad t>0 .
$$

The survival function of Weibull distribution, which is the probability that the pavement cannot be distressed at least up to time $t$, can be expressed as follows:

$$
\begin{aligned}
S(t) & =P(T \geq t) \\
& =1-F(t)=e^{-(\lambda t)^{\beta}}, \quad t>0 .
\end{aligned}
$$

The hazard rate function is corresponding to the probability that failures occur at the short interval $[t, t+\Delta t)$, as $\Delta t$ approaches zero. The hazard rate function for a Weibull distribution is

$$
\begin{aligned}
h(t) & =\lim _{\Delta t \longrightarrow 0} \frac{\operatorname{Pr}(t \leq T<t+\Delta t \mid T \geq t)}{\Delta t} \\
& =\frac{f(t)}{S(t)} \\
& =\lambda \beta(\lambda t)^{\beta-1} .
\end{aligned}
$$

Weibull distribution has a great variety of the shapes and is capable of describing the decreasing or increasing hazard rate of sample failure [14]. The hazard rate can be varied with the shape parameter $\beta$. A value of $\beta>1$ indicates that the failure rate will increase with time and will decrease if $\beta<1$.

Weibull distribution is believed to be more advantageous to describe the formulation of pavement distress than exponential distribution because the pavement materials' mechanical properties such as elastic modulus and modulus of rupture are all in a decreasing state with the increasing life of pavement and will increase the probability of concrete failure for CRCP. Therefore, the failure rate could not be a constant value $(\beta=1)$.

Portland cement concrete (PCC) slabs may fail in terms of transverse cracking, longitudinal cracking, faulting, spalling, etc. This research is focused on punchout, the major structural distress of CRCP. It was pointed out by Zollinger and Barenberg [15] that the nature of punchout distress is fatigue related. The performance of CRCP is mainly affected by not only concrete materials but also the base layer [16], noted that poor support conditions coupled with short transverse cracking intervals usually lead to punchout distress. The current ME pavement design guide provides an empirical calibration model as follows [17]:

$$
\mathrm{PO}=\frac{a}{1+b \cdot \mathrm{FD}^{c}}
$$

where PO denotes the total predicted number of punchouts per mile, FD is accumulated fatigue damage (due to slab bending in the transverse direction), and $a, b$, and $c$ are calibration constants for the locally or nationally calibrated model.

As suggested by Jung and Zollinger [18], the fatiguebased damage FD can be determined by

$$
\mathrm{FD}=\frac{N_{e}}{N_{f}},
$$

where $N_{e}$ is the number of equivalent single axle loads(ESALs) and $N_{f}$ is allowable equivalent traffic loads to failure.

Therefore, the survival function for CRCP can be expressed as a function of $N_{e}$ rather than survival time. $N_{e}$ is 
assumed to follow the Weibull distribution, and the probability density function is

$$
f\left(N_{e} ; \lambda, \beta\right)=\lambda \beta\left(\lambda N_{e}\right)^{\beta-1} e^{-\left(\lambda N_{e}\right)^{\beta}}, \quad N_{e} \geq 0 .
$$

Since the monitoring of distress is not consecutive, only the number $n_{j}$ occurred during each interval of $N_{e}$ $\left[N_{j-1}, N_{j}\right.$ ), and the total number of the intervals is $k+1$, and $j=1,2, \cdots, k, 0=N_{0}<N_{1}<\cdots<N_{k}<N_{k+1}=\infty$.

The probability of punchout that occurred in the interval $\left[N_{j-1}, N_{j}\right.$ ) can be expressed by

$$
\begin{aligned}
p_{j}\left(N_{e}\right) & =P\left(X \in\left[N_{j-1}, N_{j}\right)\right) \\
& =e^{-\left(\lambda N_{j-1}\right)^{\beta}}-e^{-\left(\lambda N_{j}\right)^{\beta}} .
\end{aligned}
$$

The total number of punchouts is observed in the most recent investigation is $n_{p}$, and then, the number of panel $n_{l}$ which denotes the number of concrete panels that was lost to the observation in the site was

$$
n_{l}=n_{t}-n_{p}
$$

where $n_{t}$ is the total number of panels in the life test for a LTPP test section.

The survival function of the Weibull distribution:

$$
\mathrm{S}\left(N_{e}\right)=1-F\left(N_{e}\right)=e^{-\left(\lambda N_{e}\right)^{\beta}} .
$$

2.2. Maximum Likelihood Estimation of Parameters. Maximum likelihood estimation is widely used to estimate parameters of Weibull distribution [19], and the likelihood function is

$$
L=\left(\prod_{j=1}^{k} p_{j}^{n_{j}}\right) \cdot S^{n_{l}}\left(N_{e}>N_{k}\right),
$$

$$
\log L=\sum_{j=1}^{k} n_{j} L n\left(e^{-\left(\lambda N_{j-1}\right)^{\beta}}-e^{-\left(\lambda N_{j}\right)^{\beta}}\right)-n_{l}\left(\lambda N_{k}\right)^{\beta} .
$$

We differentiate equation (12) with respect to the two unknown parameters and equal the resulting equation to zero as follows:

$$
\begin{aligned}
\frac{\partial L n L}{\partial \lambda}= & \sum_{j=1}^{k} n_{j} \frac{\beta \lambda^{\beta-1}\left[T_{j}^{\beta} e^{-\left(\lambda N_{j}\right)^{\beta}}-T_{j-1}^{\beta} e^{-\left(\lambda N_{j-1}\right)^{\beta}}\right]}{e^{-\left(\lambda N_{j-1}\right)^{\beta}}-e^{-\left(\lambda N_{j}\right)^{\beta}}}-n_{l} \beta N_{k} \cdot\left(\lambda N_{k}\right)^{\beta-1} \\
= & 0, \\
\frac{\partial L n L}{\partial \beta}= & \sum_{j=1}^{k} n_{j} \frac{\left(\lambda N_{j}\right)^{\beta} \log \left(\lambda N_{j}\right) e^{-\left(\lambda T_{j}\right)^{\beta}}-\left(\lambda N_{j-1}\right)^{\beta} \log \left(\lambda N_{j-1}\right) e^{-\left(\lambda N_{j-1}\right)^{\beta}}}{e^{-\left(\lambda N_{j-1}\right)^{\beta}}-e^{-\left(\lambda N_{j}\right)^{\beta}}} \\
& -n_{l} \operatorname{Ln}\left(\beta N_{k}\right) \cdot\left(\lambda N_{k}\right)^{\beta} \\
= & 0 .
\end{aligned}
$$

Equations (13) and (14) can be solved using the Newton method, which can solve the nonlinear system equations by the iteration method [20].

For the given equations,

$$
\begin{aligned}
& F(x)=0, \\
& F(x)=\left(f_{1}, f_{2}, \cdots, f_{n}\right)^{T} .
\end{aligned}
$$

Truncating the Taylor expansion of $f_{i}$ at $x_{0}$ after the linear terms gives

$$
f_{i}\left(x^{0}\right)+\sum_{j=1}^{n} \frac{\partial f_{i}}{\partial x_{j}}\left(x^{0}\right) \cdot\left(x_{j}-x_{j}^{0}\right) .
$$

The Newton method for the solution of a system of equations is

$$
x^{i+1}=x^{i}-J_{i}^{-1} F\left(x_{i}\right)
$$

where $J_{i}$ is the Jacobi matrix of $f$ at $x^{i}$, as shown in the following expression:

$$
\begin{aligned}
J_{i} & =F^{\prime}\left(x^{i}\right) \\
& =\left[\begin{array}{cccc}
\frac{\partial f_{1}}{\partial x_{1}^{i}} & \frac{\partial f_{1}}{\partial x_{2}^{i}} & \cdots & \frac{\partial f_{1}}{\partial x_{n}^{i}} \\
\frac{\partial f_{2}}{\partial x_{1}^{i}} & \frac{\partial f_{2}}{\partial x_{2}^{i}} & \cdots & \frac{\partial f_{2}}{\partial x_{n}^{i}} \\
\vdots & \vdots & \vdots & \vdots \\
\frac{\partial f_{n}}{\partial x_{1}^{i}} & \frac{\partial f_{n}}{\partial x_{2}^{i}} & \cdots & \frac{\partial f_{n}}{\partial x_{n}^{i}}
\end{array}\right] .
\end{aligned}
$$


2.3. Estimation of Initial Values. To ensure the convergence of the iterative methods and make it converge fast, an initial value must be estimated before the application of the Newton method.

Similar to Qian and Correa [21], assuming that the subjects that lost to the follow-up process (just as panels with punchout occurs) live up to at least halfway of the period. It was assumed that all the punchout occurred at the mid for each interval, say $N_{j}^{\prime}$ :

$$
\begin{aligned}
S\left(N_{j}^{\prime}\right) & =e^{-\left(\lambda N_{j}^{\prime}\right)^{\beta}}, \\
N_{j}^{\prime} & =\frac{\left(N_{j-1}+N_{j}\right)}{2} .
\end{aligned}
$$

Taking natural logarithm of equation (19), we obtain

$$
\left.\begin{array}{l}
\ln S\left(N_{j}^{\prime}\right)=-\left(\lambda N_{j}^{\prime}\right)^{\beta} \\
\ln \left[-\ln S\left(N_{j}^{\prime}\right)\right]=\beta \ln \lambda+\beta \ln N_{j}^{\prime}
\end{array}\right\} .
$$

Make $y=\ln \left[-\ln S\left(N_{j}^{\prime}\right)\right]$ and $x=\ln N_{j}^{\prime}$; then, equation (20) can be linearized as follows into the $y=m x+b$ format. Least square regression was employed to estimate the intercept $b$ and the slope $m$, and we get an estimation of the initial values $\beta_{0}$ and $\lambda_{0}$ :

$$
\begin{aligned}
& \beta_{0}=m, \\
& \lambda_{0}=\exp \left(\frac{b}{m}\right) .
\end{aligned}
$$

2.4. Determination of ESALs. The life of a CRCP panel is quantified as the total number of $80 \mathrm{kN}$ ESALs in the design lane that leads to the formulation of punchout. The distressed-based equivalent single axle load $\left(N_{e}\right)$ can be obtained by the methodology proposed by Chen and Zollinger [22].

\section{Validation with LTPP Data}

3.1. Summary Information of GPS-5 Test Sections. There are 85 test sections in the General Pavement Studies GPS-5 for
CRCP performance research, located in 29 states across United States of America. The collection of LTPP data has been under way since 1989 [23]. Two test sections were selected to illustrate the effectiveness of the approach introduced, as shown in Table 1. One section is from South Carolina and the other from Texas.

The number of ESALs of the two sites was determined according to the procedure proposed by Chen et al. [22] and the information in detail is shown in Table 2. Notably, continuously investigations were carried out for both the sections since 1990s to 2000s, and the number of punchouts was increasing in an almost consecutive manner during the period. Unfortunately, investigation data, since the latest investigation, which were not updated, are found and are listed in Table 2.

3.2. Number of Panels in Each Section. About $90 \%$ of punchouts were observed on PCC panels between a pair of transverse cracks with crack spacing between 0.3 and $0.9 \mathrm{~m}$ [24]; in addition, punchout was defined as the area enclosed by two closely spaced (usually $<0.9 \mathrm{~m}$ ) transverse cracks, a short longitudinal crack, and the edge of the pavement or a longitudinal joint. And, "Y" cracks that exhibit spalling, breakup, or faulting are also included [25]. Furthermore, an advanced model of punchout prediction was proposed by Jung and Zollinger [18], and the number of punchout can be determined by equation (22):

$$
N_{\mathrm{PO}}=\mathrm{NC}_{\mathrm{cs}<0.9 \mathrm{~m}} \times P_{e} \times P_{\mathrm{fc}},
$$

where $N_{\mathrm{PO}}$ is the number of punchout, $\mathrm{NC}_{\mathrm{cs}<0.9 \mathrm{~m}}$ is the number of cracks with crack spacing less than $0.9 \mathrm{~m}, P_{e}$ is probability of erosion, and $P_{\mathrm{fc}}$ is probability of fatigue cracking.

Consequently, the number of PCC panels between two transverse cracks spaced less than $0.9 \mathrm{~m}$ was taken as the total number of samples that placed in the life test, and the distribution of the transverse crack spacing was found to be possibly following the Weibull distribution. Therefore, the probability of the transverse crack spacing between LU and LL can be determined by the following expression [24]:

$$
\operatorname{Prob}\left(L_{U} \geq L \geq L_{L}\right)=100\left\{\exp \left[-\left(\frac{L_{L}-L_{\min }}{\alpha}\right)^{\gamma}\right]-\exp \left[-\left(\frac{L_{U}-L_{\min }}{\alpha}\right)^{\gamma}\right]\right\}
$$

And, the probability of crack spacing less than $0.9 \mathrm{~m}$ can be determined by

$$
\operatorname{Prob}\left(L_{U} \geq L\right)=100\left\{1-\exp \left[-\left(\frac{L_{U}-L_{\mathrm{min}}}{\alpha}\right)^{\gamma}\right]\right\} \text {. }
$$

where $\operatorname{Prob}\left(L_{U} \geq L \geq L_{L}\right)$ is probability of crack spacing between $L_{U}$ and $L_{L}(\%), L_{U}$ is the upper limit of the cracking interval $(\mathrm{m}), L_{L}$ is the lower limit of the cracking interval (m), and $L_{\min }$ is minimum length of crack spacing $(\mathrm{m})$; this value is set to be $0.2 \mathrm{~m}$ according to field investigation of transverse cracking pattern.

Here, $\alpha$ and $\gamma$ are the scale and shape parameters of the crack spacing distribution, respectively. And, the parameters presented by Selezneva et al. [24] were employed in this paper to determine the number of CRCP panels with the crack spacing less than $0.9 \mathrm{~m}$ (Table 3 ). 
TABLE 1: Summary information on LTPP data.

\begin{tabular}{lcccccrc}
\hline State & SHRP_ID & $\begin{array}{c}\text { Date open } \\
\text { to traffic }\end{array}$ & $\begin{array}{c}\text { Annual daily truck traffic } \\
\text { at beginning year }\end{array}$ & $\begin{array}{c}\text { Mean crack } \\
\text { spacing }(\mathrm{m})\end{array}$ & $\begin{array}{c}\text { Steel content } \\
(\%)\end{array}$ & $\begin{array}{c}\text { PCC thickness } \\
(\mathrm{mm})\end{array}$ & Base type \\
\hline $\begin{array}{l}\text { South } \\
\text { Carolina }\end{array}$ & $45 \_5035$ & $10 / 1 / 1975$ & 257 & 0.75 & 0.63 & $\begin{array}{c}\text { Cement-treated } \\
\text { subgrade soil }\end{array}$ \\
$\begin{array}{l}\text { Texas } \\
\text { 48_5323 }\end{array}$ & $9 / 1 / 1980$ & 768 & 0.71 & 0.61 & $\begin{array}{c}\text { HMA and lime- } \\
\text { treated soil }\end{array}$ \\
\hline
\end{tabular}

TABLE 2: Pavement performance monitoring in LTPP.

\begin{tabular}{|c|c|c|c|}
\hline State and ID & Investigation date & Number of punchouts & ESALs \\
\hline \multirow{6}{*}{ 45_5035 } & $3 / 17 / 1992$ & 21 & $8.42 \mathrm{E}+06$ \\
\hline & 6/8/1993 & 28 & $9.00 \mathrm{E}+06$ \\
\hline & $6 / 25 / 1997$ & 30 & $1.05 \mathrm{E}+07$ \\
\hline & $2 / 10 / 1999$ & 39 & $1.16 \mathrm{E}+07$ \\
\hline & $2 / 27 / 2002$ & 58 & $1.35 \mathrm{E}+07$ \\
\hline & $2 / 4 / 2003$ & 75 & $1.40 \mathrm{E}+07$ \\
\hline \multirow{6}{*}{ 48_5323 } & $6 / 11 / 1991$ & 17 & $5.44 \mathrm{E}+06$ \\
\hline & $5 / 19 / 1993$ & 22 & $6.44 \mathrm{E}+06$ \\
\hline & $8 / 10 / 1995$ & 23 & $7.44 \mathrm{E}+06$ \\
\hline & $5 / 14 / 1997$ & 39 & $8.44 \mathrm{E}+06$ \\
\hline & $6 / 16 / 1999$ & 71 & $9.45 \mathrm{E}+06$ \\
\hline & $6 / 25 / 2002$ & 55 & $1.10 \mathrm{E}+07$ \\
\hline
\end{tabular}

TABle 3: number of panels with the length less than $0.9 \mathrm{~m}$

\begin{tabular}{lcccc}
\hline Section no. & Count & $\alpha$ & $\gamma$ & $N\left(L_{0.9} \geq L\right)$ \\
\hline $45 \_5035$ & 199 & 25.887 & 1.165 & 143 \\
$48 \_5323$ & 210 & 22.860 & 1.812 & 176 \\
\hline
\end{tabular}

\section{Result and Discussion}

A numerical program in accordance with the methodology in section 2 was written to estimate the values of $\lambda$ and $\beta$. It can be seen from Table 4 that the Newton iteration converged to the root of equations very quickly, and the number of iterations is only 3 to 4 .

4.1. The Estimation of the Threshold Value of $N_{e}$ for Punchout Occurrence. The threshold value of $N_{e}$ is the equivalent traffic loads under which the probability of the occurrence of punchout is zero; then, the function can be expressed as follows:

$$
\begin{array}{ll}
F\left(N_{e}\right)=0, & N_{e} \leq N_{e 0}, \\
F\left(N_{e}\right)=1-e^{-\left[\lambda\left(N_{e}-N_{e 0}\right)\right]^{\beta}}, & N_{e}>N_{e 0} .
\end{array}
$$

With the values of $\lambda \beta$ in Table 4 , it is advantageous to estimate the value of $N_{e 0}$ by the iteration method to find the minimum standard deviation of the predicted number of punchout. The standard deviation of the predicted results under a series of $N_{e 0}^{\prime}$ can be determined by equations (26) and (27):

$$
\begin{aligned}
\sigma & =\sqrt{\sum_{i=1}^{N} \frac{\left(\mathrm{POU}_{\mathrm{oi}}-\mathrm{POU}_{\mathrm{pi}}\right)^{2}}{N}}, \\
\mathrm{POU}_{\mathrm{pi}} & =\mathrm{NC}_{\mathrm{cs}<0.9 \mathrm{~m}} \times\left(1-e^{-\left[\lambda\left(N_{e}-N_{e}^{\prime}\right)\right]^{\beta}}\right) .
\end{aligned}
$$

TABle 4: Estimation of the shape and scale parameters.

\begin{tabular}{cccccc}
\hline \multirow{2}{*}{ Section no. } & \multicolumn{2}{c}{ Initial value } & \multicolumn{2}{c}{ Solutions } & Number of \\
& $\lambda 0$ & $\beta 0$ & $\lambda$ & $\beta$ & iterations \\
\hline $45 \_5035$ & 0.0434 & 1.3067 & 0.0560 & 1.3193 & 3 \\
$48 \_5323$ & 0.0326 & 1.0956 & 0.0690 & 1.1868 & 4 \\
\hline
\end{tabular}

where $\sigma$ is standard deviation, $N$ is the number of pavement performance investigation, $\mathrm{POU}_{\mathrm{oi}}$ is the number of punchouts recorded at the investigation $i, \mathrm{POU}_{\mathrm{pi}}$ is the predicted number of punchouts for investigation $i$, and $N_{e 0}^{\prime}$ is the assigned value of $N_{e O}$ in the literation.

The value of $N_{e O}$ should be in the range of $\left[0, N_{e 1}\right)$, where $N_{e 1}$ is the equivalent traffic loads when the $1^{\text {st }}$ investigation with punchouts is conducted. Substitute a series of $N_{e 0}^{\prime}$ into (28) to calculate $\sigma$ for each ease of $N_{e 0}^{\prime}$, as shown in Figures 1 and 2.

4.2. Hazard Function. The shape parameters $\beta$ of both the test sections are greater than 1 , which indicates that the hazard rate of occurrence of punchout will increase with the accumulation of ESALs (Figures 3 and 4). In practice, the probability of fatigue cracking as well as that of base erosion with the time elapsing is increasing. The potential of punchout occurrence will increase as a result of the deterioration of the pavement structure. Theoretically, the estimation of the characteristic assuming Weibull distribution agrees well with the engineering practice. The punchout of CRCP is expressed as the product of probability of base erosion and the probability of fatigue cracking, as shown in equation (22). Interestingly, the base types of Section 455035 and Section 48-5323 are cement-treated base (CTB) and hot mix asphalt (HMA), respectively. Comparing 


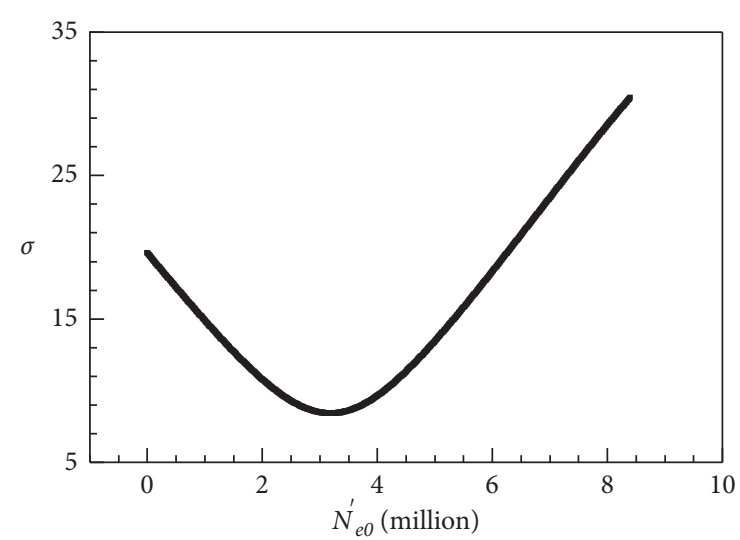

Figure 1: Determination of $N_{e 0}$ for 45_5035.

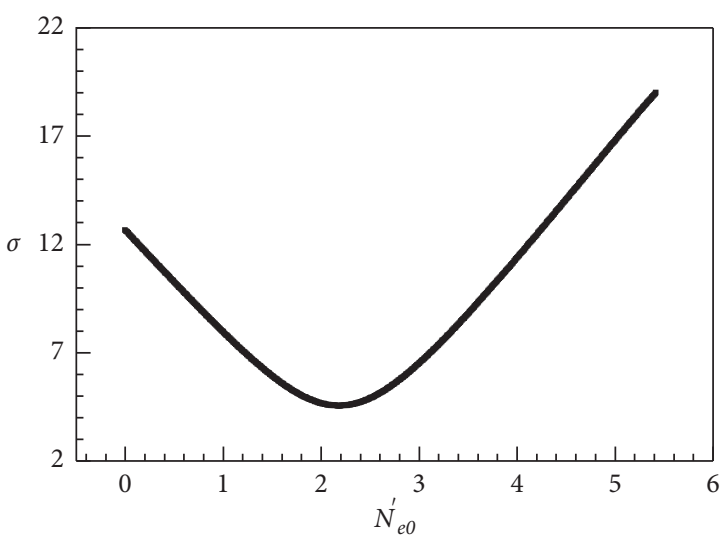

Figure 2: Determination of $N_{e 0}$ for $48 \_5323$.

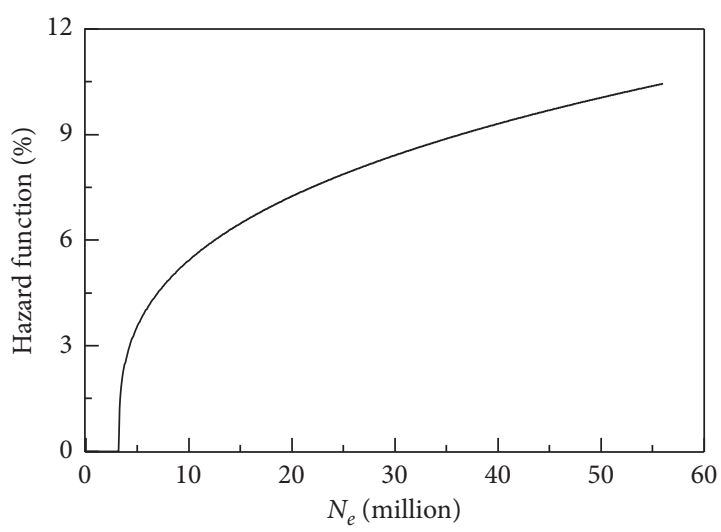

FIgURE 3: Hazard function for site 45_5035.

Figures 3 and 4, it obviously shows that the hazard rate of CRCP with CTB base increases much more rapidly than that supported by asphalt treated base (ATB) when $\mathrm{Ne}$ is less than 10 million. Thus, from the hazard rate prediction, the type of base has presumably decisive influence on the formulation of punchout. Actually, ATB exhibits much better resistance of erosion than $\mathrm{CTB}[26,27]$.

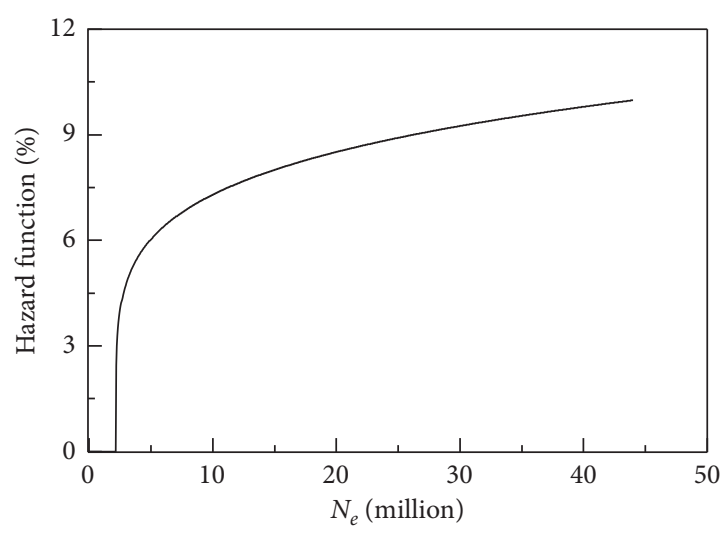

Figure 4: Hazard function for site 48_5323.

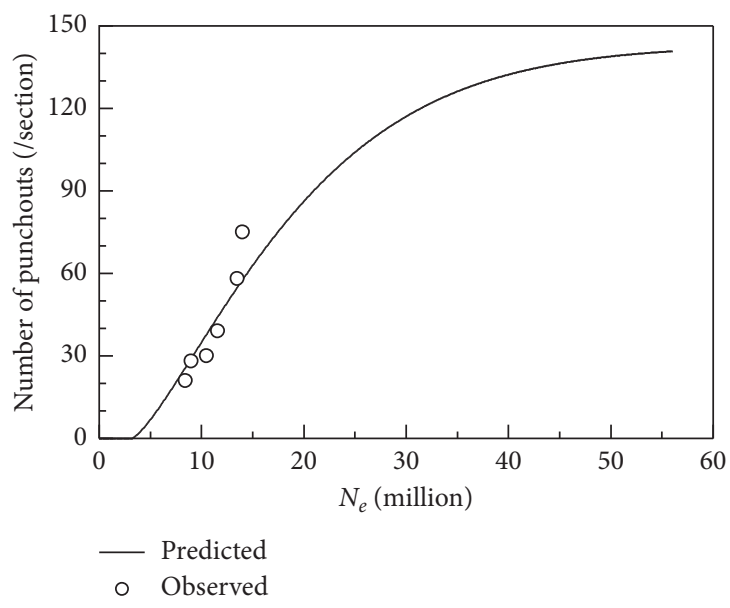

Figure 5: Prediction with Weibull fitting for site 45_5035.

4.3. Distribution Function. The most concerned application of the pavement performance is the perdition of the level of distress, for instance, number of punchouts for CRCP. The prediction result will help the highway agencies in the decision-making processes related to the maintenance and rehabilitation. In Texas, USA, four levels of treatment are required: (1) preventive maintenance, (2) light rehabilitation, (3) medium rehabilitation, and (4) heavy rehabilitation or reconstruction [28]. The highway agencies may set a limit of number of punchout per unit length, for instance, 10 punchouts $/ \mathrm{km}$, at which a preventive pavement maintenance needs to be performed.

As the scale and shape parameters have been determined, it is possible to predict the number of punchouts at a specific traffic level $N_{j}$ :

$$
N_{\mathrm{PO}}=\mathrm{NC}_{\mathrm{cs}<0.9 \mathrm{~m}} \cdot\left[1-\exp \left(-\left(\lambda \cdot N_{j}\right)^{\beta}\right)\right] \text {, }
$$

where $N_{\text {PO }}$ is the number of punchout at a specific traffic level $N_{j}$;

As it is shown in Figures 5 and 6, the predicted number of punchouts matches very well with the values from field investigations, and the proposed approach provides a reliable pavement performance-forecasting model. 


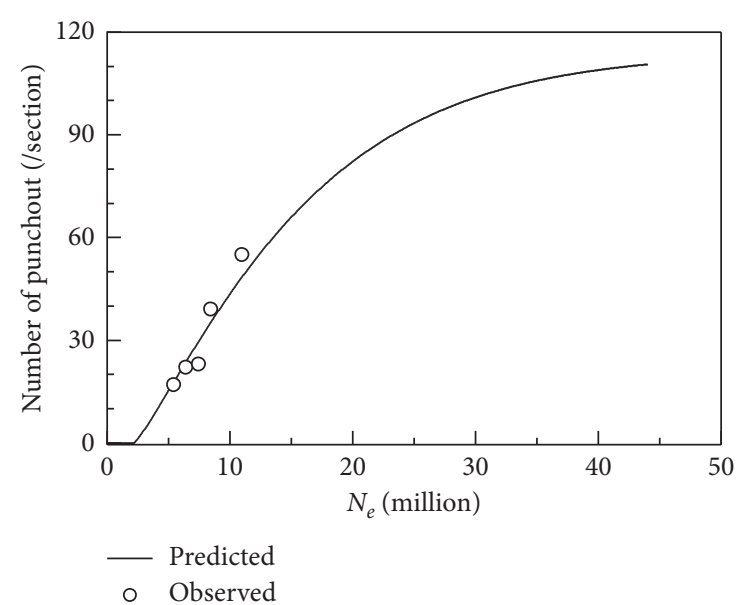

Figure 6: Prediction with Weibull fitting for site 48_5323.

4.4. Discussion. The number and accuracy of the LTPP observation datasets play a key role on the reliability and validity of pavements' survival analysis. Unfortunately, the punchouts of CRCP has not been continuously monitored since latest investigation in 2000s for the two sections. Extensive research need to be conducted when some new datasets can be obtained.

\section{Conclusions}

In this study, an advanced calibration model for punchout distress in CRCP was proposed. Considering that LTPP database only records the number of punchouts occurred in each interval, which was recognized as grouped data, the number of ESALs was assumed to follow Weibull distribution. The maximum likelihood estimation was proposed to determine the parameters in Weibull distribution. The proposed calibration model was validated with the data from two test sections in LTPP database. The following conclusions can be drawn:

(i) The number of ESALs that leads to punchout distress is found to follow the Weibull distribution

(ii) The maximum likelihood estimation is effective in determining the parameters of the Weibull distribution

(iii) The proposed calibration model is capable of describing the punchout and can be employed to predict the failure rate and reliability of CRCP in the pavement design and arrangement of rehabilitation activities

\section{Data Availability}

Some or all data, models, or code generated or used during the study are available from the corresponding author by reasonable request.

\section{Conflicts of Interest}

The authors declare that they have no conflicts of interest.

\section{Acknowledgments}

The authors appreciate the generous help and constructive ideas from Dr. Dan G. Zollinger in Texas A\&M University. This research was funded by Science and Technology Innovation Program of the Department of Transportation, Yunnan Province, (Grant no. [2020]15-1), Yunnan Fundamental Research Projects (Grant no. 2019FD004), and Applied Basic Research Foundation of Yunnan Province (Grant no. 2016FB099)

\section{References}

[1] J. A. Prozzi and S. M. Madanat, "Using duration models to analyze experimental pavement failure data," Transportation Research Record: Journal of the Transportation Research Board, vol. 1699, no. 1, pp. 87-94, 2000.

[2] H. L. V. Quintus, M. I. Darter, and J. Mallela, Local Calibration Guide for the Recommended Guide for MechanisticEmpirical Design of New and Rehabilitated Pavement Structures, Applied Research Associates, Inc.: Roud Rock, Texas, USA, 2003.

[3] C. Rao, O. Selezneva, M. I. Darter, L. T. Glover, and L. Khazanovich, "Calibration of mechanistic-empirical performance model for continuously reinforced concrete pavement punch-outs," Transportation Research Record: Journal of the Transportation Research Board, vol. 1896, no. 1, pp. 15-22, 2004.

[4] Y. J. Jiang and M. I. Darter, "Factors affecting rigid pavement performance: evaluation of the LTPP SPS-2 experiment," in Proceedings of Geotechnical Engineering for Transportation Projects, pp. 1050-1057, CA, USA, July 2004.

[5] J. J. Hajek and T. J. Kazmierowski, "Use of long-term pavement performance data for calibration of pavement design models," Transportation Research Record: Journal of the Transportation Research Board, vol. 1778, no. 1, pp. 149155,2001

[6] A. Banerjee, J. P. M. Aguiar, and J. A. Prozzi, "Calibration of mechanistic-empirical pavement design guide permanent deformation models," Transportation Research Record: Journal of the Transportation Research Board, vol. 2094, no. 1, pp. 12-20, 2009.

[7] Y. Wang, K. C. Mahboub, and D. E. Hancher, "Survival analysis of fatigue cracking for flexible pavements based on long-term pavement performance data," Journal of Transportation Engineering, vol. 131, no. 8, pp. 608-616, 2005.

[8] Q. Dong and B. Huang, "Failure probability of resurfaced preventive maintenance treatments," Transportation Research Record: Journal of the Transportation Research Board, vol. 2481, no. 1, pp. 65-74, 2015.

[9] Q. Dong, B. Huang, and S. Richards, "Evaluation of influence factors on crack initiation of LTPP resurfaced-asphalt pavements using parametric survival analysis," Journal of Performance of Constructed Facilities, vol. 28, no. 2, pp. 412-421, 2014.

[10] J. A. Prozzi and S. M. Madanat, "Using duration models to analyze experimental pavement failure data," Transportation Research Record: Journal of the Transportation Research Board, vol. 1699, no. 1, pp. 87-94, 2000.

[11] W. Weibull and S. Sweden, "A statistical distribution function of wide applicability," Journal of Applied Mechanics, vol. 18, no. 3, pp. 293-297, 1951. 
[12] J. F. Lawless, Statistical Models and Methods for Lifetime Data, John Wiley\& .Sons,Inc, NJ, USA, 1982.

[13] B.-W. Tsai, J. T. Harvey, and C. L. Monismith, "Application of Weibull theory in prediction of asphalt concrete fatigue performance," Transportation Research Record: Journal of the Transportation Research Board, vol. 1832, no. 1, pp. 121-130, 2003.

[14] S. J. Almalki and S. Nadarajah, "Modifications of the Weibull distribution: a review," Reliability Engineering \& System Safety, vol. 124, pp. 32-55, 2014.

[15] D. G. Zollinger and E. J. Barenberg, Continuously Reinforced Pavements:Punchouts And Other Distresses And Implications For Design; FHWA/IL/UI 227, University of Illinois, Urbaba, IL, 1990

[16] X. Shi, A. Mukhopadhyay, and D. Zollinger, "Long-term performance evaluation of concrete pavements containing recycled concrete aggregate in Oklahoma," Transportation Research Record: Journal of the Transportation Research Board, vol. 2673, no. 5, pp. 429-442, 2019.

[17] I. Ara, ERES Consultants Division. Guide For MechanisticEmpirical Design Of Newand Rehabilitated Pavement Structures, Washington D.C., USA, 2004.

[18] Y. S. Jung, D. G. Zollinger, and B. M. Ehsanul, "Improved mechanistic-empirical continuously reinforced concrete pavement design approach with modified punchout model," Transportation Research Record: Journal of the Transportation Research Board, vol. 2305, no. 1, pp. 32-42, 2012.

[19] N. Balakrishnan and M. Kateri, "On the maximum likelihood estimation of parameters of Weibull distribution based on complete and censored data," Statistics and Probability Letters, vol. 78, no. 17, pp. 2971-2975, 2008.

[20] W. Gautschi, Numerical Analysis, Springer, New York, NY, USA, 2nd edition, 2012.

[21] L. Qian and J. Correa, "Estimation of Weibull parameters for grouped data with competing risks," Journal of Statistical Computation and Simulation, vol. 73, no. 4, pp. 261-275, 2003.

[22] L. Chen, D. G. Zollinger, and B. Tian, "Approach to local calibration of an advanced model for punchout distress using LTPP data," Journal of Transportation Engineering, vol. 141, no. 8, Article ID 04015014, 2015.

[23] S. D. Tayabji, O. Selezneva, and Y. J. Jiang, Preliminary Evaluation Of LTPP Continuoulsy Reinforced Concrete (CRC) Pavement Test Section; FHWA-RD-99-086, pp. 1-3, ERES Consultants, Inc., Columbia, Maryland, 1999.

[24] O. Selezneva, M. Darter, D. Zollinger, and S. Shoukry, "Characterization of transverse cracking spatial variability: use of long-term pavement performance data for continuously reinforced concrete pavement design," Transportation Research Record: Journal of the Transportation Research Board, vol. 1849, no. 1, pp. 147-155, 2003.

[25] J. S. Miller and W. Y. Bellinger, Distress Identification Manual For the Long-Term Pavement Performance Program; FHWARD-03-031; Office of Infrastructure Research and Developement, pp. 77-79, Federal Highway Administration, McLean, VA, USA, June 2003.

[26] Y. Jung, Advancement of Erosion Testing, Modeling, and Design of Concrete Pavement Subbase Layers, Texas A\&M University, College Station, Texas, United States, 2010.

[27] Y. S. Jung, D. G. Zollinger, and A. J. Wimsatt, “Test method and model development of subbase erosion for concrete pavement design," Transportation Research Record: Journal of the Transportation Research Board, vol. 2154, no. 1, pp. 22-31, 2010 .
[28] A. M. Ioannides and P. K. Tallapragada, "An overview and A case study of pavement performance prediction," International Journal of Pavement Engineering, vol. 14, no. 7, pp. 629-644, 2013. 